\title{
Erratum to: Point source identification using a simple permutation test: a case study of elevated PCDD/F levels in ambient air and soil and their relation to the distance to a local municipal solid waste incinerator
}

\author{
Chu-Chih Chen $\cdot$ Kuen-Yuh Wu • \\ Guo-Ping Chang-Chien
}

Published online: 26 May 2012

(c) Springer-Verlag 2012

Erratum to: Stoch Environ Res Risk Assess (2012)

\section{6:225-233}

DOI 10.1007/s00477-011-0492-6

Unfortunately this article has been published before in Stochastic Environmental Research and Risk Assessment. The first publication of this article was in Stochastic Environmental Research and Risk Assessment 25:7, pp. 929-937, DOI 10.1007/s00477-010-0449-1. Springer apologizes for this double publication of the article and recommends to use the first publication for referencing.

The online version of the original article can be found under doi: 10.1007/s00477-011-0492-6.

C.-C. Chen $(\bowtie)$

Division of Biostatistics and Bioinformatics, Institute of Population Health Sciences, National Health Research Institutes, Zhunan, Taiwan

e-mail: ccchen@nhri.org.tw

K.-Y. Wu

Institute of Occupational Medicine and Industrial Hygiene,

School of Public Health, National Taiwan University,

Taipei, Taiwan

G.-P. Chang-Chien

Department of Chemical and Materials Engineering,

Cheng-Shiu University, Kaohsiung, Taiwan 